\title{
Enhancement of cellulolytic enzymes and xylanase production via classical mutational techniques under solid-state fermentation condition
}

\author{
Tai Wan $\mathrm{Yi}^{1}$, Lee Chee Keong ${ }^{1 *}$, Darah Ibrahim ${ }^{2}$ \\ ${ }^{1}$ School of Industrial Technology, Universiti Sains Malaysia, 11800 USM, Penang, Malaysia. \\ ${ }^{2}$ Industrial Biotechnology Research Laboratory, School of Biological sciences, Universiti Sains Malaysia, 11800 \\ USM, Penang, Malaysia. \\ Email: cklee@usm.my; cklee1311@yahoo.co.uk
}

Received 1 June 2015; Received in revised 18 August 2015 form; Accepted 18 August 2015

\begin{abstract}
Aims: High cost of cellulases remains the most significant barrier to the economical production of bio-ethanol from lignocellulosic biomass (LB). The present study aims at developing a local cellulolytic fungal strain through random mutagenesis coupled with the feasibility of solid-state fermentation (SSF) by utilizing agricultural wastes such as oil palm frond (OPF) as the substrate.

Methodology and results: Out of 95 wild isolates tested, native fungal strain Aspergillus niger, designated DWA8 was isolated as the top enzymatic secretor. For quantitative enzyme analysis, SSF was conducted using $1 \times 10^{6} \mathrm{spore} / \mathrm{mL}$ inoculated onto $5 \mathrm{~g}$ of ground OPF, incubated at room temperature for 7 days, with $70 \%$ moisture content and an initial medium $\mathrm{pH}$ of 7 . Random mutagenesis has always been tempting in the enhancement of enzyme production. In this work, the compounded treatment of microwave, ultraviolet (UVC) and Ethyl Methanesulfonate (EMS) have generated an Aspergillus niger MUE3.06 mutant with an overall increase of $114 \%$ in CMCase activity, approximately $70 \%$ in FPase and Xylanase activity respectively compared with the parental DWA8 strain. Thus this finding is capable to be fully developed as an established mutational scheme to create highly productive filamentous fungus in a cheap, simple and sustainable way.

Conclusion, significance and impact of study: It was the first attempt to explore the combine effect of the three popular mutagens upon cellulases and xylanases. It is believed that more diversified of mutagen types induce more diversified mutation pattern (with instructive planning), which is very desirable in creating new enzymes with novel abilities.
\end{abstract}

Keywords: Lignocellulosic biomass, solid-state fermentation, cellulase, Aspergillus, conventional random mutation

\section{INTRODUCTION}

Lignocellulosic biomass (LB) such as woods, straws and husks serve as the raw materials for the secondgeneration bioethanol (SGB) production (Balat, 2011; Goh et al., 2010). In Malaysia, most of this LB waste come from oil palm plantation. In this case, oil palm frond (OPF) which contains high cellulose content (62\%) but low lignin portion (15\%) could be the ideal feedstock for SGB. Trichoderma and Aspergillus species are the two most well-known cellulase producers that belong to the fungal kingdom. To achieve complete hydrolysis of cellulose in LB, a cellulase multi-enzyme protein which composed of cellobiohydrolase/ exoglucanase (EC 3.2.1.74), endoglucanase/cellulases (EC 3.2.1.4) and $\beta$-glucosidase (EC 3.2.1.21) is needed (Chand et al., 2005; He et al., 2009). Apart from cellulose, hemicellulose is another heterogenous polysaccharides building plant secondary cell wall and the major enzymes responsible for its degradation are the xylanases (Polizeli et al., 2005).
In the continuous effort to enhance the amount and quality of these enzymes, random mutagenesis is an ageold yet successful methods (He et al., 2009). It is still remained attractive in the advent of many other advanced techniques such as genetic modification and directed evolution as it generates stable changes in the genomes of host organisms without much prior knowledge of the cellular mechanism or genetic make-up required (Derkx et al., 2014). Being one of the most widely used techniques to generate optimized microorganisms over the last decades, mutagenesis has been applied to improve both monogenic and polygenic traits (Steensels et al., 2014). Hence, for complex phenotypes like the production of cellulolytic enzyme consortium in a high concentration, this technique is especially beneficial in generating mutants that carry multiple mutations under high dosage. Moreover, in recent studies, mutagenesis is often the first step to generate genetic variation in the population, after which genome shuffling of the best-performing mutants is

*Corresponding author 
applied, or the mutant population is subjected to directed evolution (Steensels et al., 2014).

Mutagenesis is described as the exposure or treatment of biological material to a mutagen, for instances, a physical or chemical agent that raises the frequency of mutation above the spontaneous rate (Kodym and Afza, 2003). Some of the most important physical mutagens include electromagnetic radiation, such as gamma rays, X-rays, UV light and particle radiation such as fast and thermal neutrons, alpha and beta particles. Many of the early systemic molecular studies of DNA damage and mutagenesis used UV and our understanding of its effects is probably the most extensive (Ennis, 2001). Besides causing the loss of viability or reproduction of microorganisms due to the breakage of double DNA strands by inducing primary base damage or alteration (Dose et al., 1996; Nourmoradi et al., 2012), this type of DNA disruption could also result in the overexpression of cellulase genes (Shafique et al., 2011). The latter effect has made UVC light being appreciated and thus employed in this experiment. Chemical mutagens include alkylating agents, intercalating agents and base analogues. EMS has been shown to be a very effective and efficient mutagen and has probably become the most popular chemical mutagen (Kodym and Afza, 2003). Our research attempted to obtain various types of genetic changes through the combined action of three different mutagen types.

Therefore, this research is aimed at discovering potential cellulase-producing local fungal strain by excessive screening procedures, and creating hyperproducing mutant strain via mutational techniques and SSF technology.

\section{MATERIALS AND METHODS}

\section{Preliminary screening and isolation of native fungal strains}

Sample collection of fungal isolates came from several environmental sources such as decay wood materials, rotten fruits, soil particles from agricultural plantation and certain parts of the local crops in Ayer Puteh Dalam, Pendang, Kedah, Malaysia. Cellulose agar selective medium was used in the initial step to screen for cellulase producers. The composition of cellulose agar medium was as followed \% (w/v): a-cellulose, 3\%; sodium nitrate, $0.3 \%$; ammonium sulphate, $0.1 \%$; potassium dihydrogen phosphate, $0.1 \%$; ammonium hydrogen phosphate, $0.05 \%$; magnesium sulphate, $0.01 \%$; Bacto Agar, $2 \%$ and yeast extract, $0.03 \%$. The $\mathrm{pH}$ of the medium was adjusted to 6.5 before autoclave. In this experiment, addition of antibiotics such as tetracycline to inhibit bacterial growth was not needed as cellulose itself is a hard carbon source to be digested, and only those cellulolytic microbes could feed on it. Plates were continuously observed for the growth and morphology of the fungus for 7 days. Isolates that grew on the agar were further purified by subculturing onto potato dextrose agar (PDA) supplemented with $0.05 \%(\mathrm{v} / \mathrm{v})$ Triton $\mathrm{X}-100$ to obtain a pure single fungal colony. For maintenance purpose, single colonies isolated were then transferred to PDA slants and incubated under $30{ }^{\circ} \mathrm{C}$ until sufficient growth. Then, cultures were stored at $4{ }^{\circ} \mathrm{C}$ prior usage.

\section{Cellulase production in submerged fermentation}

All (79) isolates that could grow on cellulose agar selective medium were further evaluated for the confirmation of their cellulase production potential. These isolates were used as the inoculums during submerged fermentation. For inoculum preparation, fungal isolates were revived in PDA slants at $30{ }^{\circ} \mathrm{C}$. The spores were harvested after 4-5 days of cultivation with sterile distilled water containing $0.1 \%(\mathrm{w} / \mathrm{v})$ Tween-80 (Smits et al., 1996). Spore concentration was estimated and adjusted to $1 \times 10^{6}$ spores $/ \mathrm{mL}$ by direct microscopecounting using hemocytometer (Raimbault and Alazard, 1980). The modified minimal liquid media composed of $(\mathrm{g} / \mathrm{L})$ : $\alpha$ cellulose, 20; potassium dihydrogen phosphate, 1 and magnesium sulphate 0.1 (Taneja et al., 2002). Each Erlenmeyer flask $(250 \mathrm{~mL})$ containing $99 \mathrm{~mL}$ of liquid media was inoculated with $1 \%$ of spore suspension with aforementioned concentration. Incubation was carried out in orbital shaker at $30{ }^{\circ} \mathrm{C}, 150 \mathrm{rpm}$ for 7 days. After incubation, fermentation broth was centrifuged at 6000 rpm for $15 \mathrm{~min}$ and $0.2 \mathrm{~mL}$ supernatant was used to detect the presence of cellulase based on its halo appearance during carboxylmethylcellulose (CMC) qualitative agar plate screening (Theather and Wood, 1982). After pipetting the supernatant into a well in each CMC agar plate, incubation was carried out for 2 days under room temperature. Clear zones formed as a result of $\mathrm{CMC}$ hydrolysis were visualized by Congo red flooding and stabilized by $1 \mathrm{M}$ hydrochloric acid $(\mathrm{HCl})$ flooding.

Selection of potential cellulases producer via solidstate fermentation

Fungal isolates with clear zone $>2 \mathrm{~cm}$ diameter (data not shown) obtained from previous experiment were further assessed for their enzymatic activities via solid-state fermentation (SSF), in order to confirm primary selection analysis. Oil palm frond (OPF) which was used as substrate in SSF was prepared from freshly-plucked frond from palm oil plantation. After washing and drying, the chopped frond was ground and collected after passing through $4 \mathrm{~mm}$ filtering steel mesh. The composition of the SSF medium was made of $(\mathrm{g} / \mathrm{L})$ : ammonium nitrate, 5.0; potassium dihydrogen phosphate, 5.0; corn steep liquor, 2.0; sodium chloride, 1.0; magnesium sulphate, 1.0 and trace elements $(\mathrm{mg} / \mathrm{L})$; iron sulphate, 5.0 ; manganese sulphate, 1.6; zinc sulphate, 3.5 and cobalt chloride, 2.0 (Pang et al., 2006). Fungal cultivation was carried out in a $250 \mathrm{~mL}$ cotton plugged Erlenmeyer flasks, consisted of autoclaved $5 \mathrm{~g}$ OPF powder and $70 \%(\mathrm{w} / \mathrm{w})$ growth media inoculated with $20 \%(\mathrm{w} / \mathrm{v})$ suspension with concentration prepared as aforementioned. The contents of the flasks were mixed thoroughly and incubated at room temperature for 1 week so that complete fungal growth for DWA8 was allowed. 


\section{Extraction of enzyme}

After fermentation, samples were mixed with distilled water containing $0.1 \%(\mathrm{w} / \mathrm{v})$ Tween 80 . The mixture was allowed to soak at room temperature for $2 \mathrm{~h}$, with occasional hand swirling at every 30-minute interval. Then, the fermented substrates were separated from the enzymatic solution by filtration through Whatman No. 1 filter paper. The filtrate was used as the source of crude enzyme to be tested for the three enzyme activities (FPase, CMCase and Xylanase). Based on the enzymes activities, the most promising enzymatic producer was selected for further use in mutational development studies.

\section{Preparation and selection of mutant}

\section{Microwave treatment}

Selected isolate was grown on PDA slant for two days under $30{ }^{\circ} \mathrm{C}$. Spore suspension was prepared by flooding the culture slant filled with mature black conidia with $0.1 \%$ Tween-80, and cell count was adjusted to $5 \times 10^{3}$ pores $/ \mathrm{mL}$. A volume of $5 \mathrm{~mL}$ of this suspension was then transferred into a sterile empty Petri dish to be treated with microwave irradiation. Within a household microwave, the Petri dish was put into a water-bath filled with ice-cold water to reduce the effect of heat generated from the $1000 \mathrm{~W}, 50 \mathrm{~Hz}$ Panasonic 27L NNGD-570S microwave oven, so that the microwave irradiation became the sole factor in contributing to the spore killing. New batch of ice-cold water was added at every $30 \mathrm{sec}$ to maintain the water temperature surrounding the spore suspension throughout the entire 180 -second treatment. Then, $0.05 \mathrm{~mL}$ of the suspension was removed at every 30 -second interval starting from 0 -second (the control) until $180 \mathrm{sec}$. They were spread onto screening plate and incubated under $30^{\circ} \mathrm{C}$ for two days ( $\mathrm{Li}$ et al., 2010 with some modifications). The screening media was formulated by $0.1 \% \mathrm{CMC}$ as the carbon source, and $0.5 \%$ Triton $\mathrm{X}$ 100 in restricting colony size supplemented by PDA powder to trigger the fungal colony appearance. In this way, the incubation period could be shortened. After two days, the numbers of colonies appeared on the control plates and survived on mutant plates were counted. Mutant colonies were picked from the plates which showed relatively high lethality rate, and they were used to hydrolyze ground OPF during one-week SSF. The most-promising mutant was chosen based on the performance of the enzyme activities.

\section{Ultraviolet treatment}

After microwave treatment, UV mutation was induced by $100 \mathrm{~W}, 253.7 \mathrm{~nm}$ Germicidal UV lamp manufactured by Sankyo Denki Co., LTD. The UV light was shone upon the open-lid Petri dish filled with spore suspension with a distance of $45 \mathrm{~cm}$. The spores were UV-treated for $10 \mathrm{~min}$ starting from 0-minute (the control), with an interval of 2 min (Kovacs et al., 2008 with some modifications). For fungal strain preparation and best mutant selection, the experiments were carried out according to the microwave method described before.

\section{Chemical treatment}

Chemical mutagenesis was carried out by adding EMS (M0880, Sigma) liquid directly into the spore suspension. Spore suspension was prepared in the same way, while EMS concentration was prepared in the range of $1.0-3.0 \%$ $(\mathrm{v} / \mathrm{v})$ in $0.5 \%(\mathrm{v} / \mathrm{v})$ interval. The total volume of each of the mutagenesis mix consisted of these two solution was 3 $\mathrm{mL}$, and the reaction took place in a $10 \mathrm{~mL}$ universal bottle. These bottles were incubated at $30^{\circ} \mathrm{C}$ for $8 \mathrm{~h}$ and shaken at $150 \mathrm{rpm}$ (Toyama and Toyama, 2000; Barbour et al., 2006 with some modifications). Approximately $50 \mu \mathrm{L}$ of treated spore suspensions were directly plated onto the same screening media used during physical mutagenesis. The untreated spore suspension served as the control. After 2-day incubation at $30{ }^{\circ} \mathrm{C}$, colonies grew on the plates which showed lethality rate more than $90 \%$ were picked and further purified on PDA plate. Then, these sporulated isolates were used as the inoculums for SSF utilizing OPF as the substrate.

\section{Determination of FPase (filter paperase) activity}

The cellulase activity also can be measured as FPase Activity Units (Ghose, 1987). A $1 \times 6 \mathrm{~cm}$ strip of Whatman No. 1 filter paper was added to a solution containing 0.5 $\mathrm{mL}$ of enzyme supernatant and $1.0 \mathrm{~mL}$ of $50 \mathrm{mM}$ citric$\mathrm{NaOH}$ buffer $(\mathrm{pH} 4.5)$. The mixture was incubated for $1 \mathrm{~h}$ at $60{ }^{\circ} \mathrm{C}$. The reaction was terminated by adding $3 \mathrm{~mL}$ of DNS solution, followed by $5 \mathrm{~min}$ of boiling. After cooling, $20.0 \mathrm{~mL}$ of distilled water was added and the absorbance was read at $540 \mathrm{~nm}$ using glucose as standard. The heatinactivated enzyme samples were use as the controls for this enzyme assay. One unit of cellulase activity was defined as the amount of enzyme that released $1 \mu \mathrm{mol}$ of reducing sugar equivalent to glucose per minute under the above assayed condition. The enzyme activity was expressed as unit (U) per $\mathrm{g}$ of fermented OPF.

\section{Determination of CMCase (carboxymethycellulase) activity}

CMCase activity was carried out according to Gessesse and Gashaw (1999). Carboxymethylcellulose was dissolved in citric- $\mathrm{NaOH}$ buffer $(50 \mathrm{mM}, \mathrm{pH} 4.5)$ at $1 \%$ $(\mathrm{w} / \mathrm{v})$. Then, $0.5 \mathrm{~mL}$ of appropriately diluted enzyme was added to $1.0 \mathrm{~mL}$ of $\mathrm{CMC}$ solution. The mixture was incubated at $55{ }^{\circ} \mathrm{C}$ for $20 \mathrm{~min}$. The reaction was terminated by adding $3.0 \mathrm{~mL}$ of dinitrosalicylic acid (DNS) reagent followed by boiling for $5 \mathrm{~min}$. The released sugar was measured spectrophotometrically at $575 \mathrm{~nm}$ using glucose as the standard. The controlled experiment was performed using heat-inactivated enzyme. One unit of cellulase activity was defined as the amount of enzyme that released $1 \mu \mathrm{mol}$ of reducing sugar equivalent to glucose per minute under the above assayed condition. The enzyme activity was expressed as unit (U) per $g$ of fermented OPF.

\section{Determination of xylanase activity}

Xylanase activity was assayed as described by Gessesse and Gashe (1997). The experiment was performed 
similarly with CMCase assay except $1 \%(\mathrm{w} / \mathrm{v})$ of oat spelt xylan was used instead of CMC with $50{ }^{\circ} \mathrm{C}$ as the incubation temperature. Xylose was used as the standard instead of glucose.

\section{Determination of fungal growth and moisture content}

The growth of the fungus was examined by measuring the glucosamine content of the fungus as described by Swift (1972). The glucosamine concentrations in different samples were measured spectrophotometrically at 530 $\mathrm{nm}$ using glucosamine as the standard. The moisture content of the SSF substrate (OPF) was determined by measuring the change of weight of approximately $4.0 \mathrm{~g}$ of fermented OPF before and after drying in an oven at 80 ${ }^{\circ} \mathrm{C}$ for at least $48 \mathrm{~h}$ (Nagel et al., 2001).

\section{Fungal strain identification}

Fungal biomass was obtained by inoculating a loopful of matured blackish spores into the $100 \mathrm{~mL}$ potato dextrose broth. This $250 \mathrm{~mL}$ Erlenmeyer flask was then incubated at $30{ }^{\circ} \mathrm{C}$ while shaking at $100 \mathrm{rpm}$ for 3 days. The mycelium was harvested by filtration through Whatman No. 1 filter paper, washed with distilled water, freeze-dried and stored in the freezer. For DNA extraction, the freezedried mycelium was ground to a fine powder using liquid nitrogen in a pre-cooled pestle, while the rest of the procedure was carried out using Plant DNA Rapid Extraction Kit (spin-column) (BioTeke Corporation, China). For polymerase chain reaction (PCR) amplification, $2 \mu \mathrm{L}$ of fungal DNA were added to the PCR master mixture, which consisted of $5 \mu \mathrm{L}$ of $10 \times$ reaction buffer, $4 \mu \mathrm{L}$ of $10 \mathrm{mM}$ dNTPs mixture and 2 units of Prime Taq $^{\text {TM }}$ DNA Polymerase (Genet Bio, Korea) for a total volume of $50 \mu \mathrm{L}$ (manufacturer's instruction). The primers used were U1F (5'-CTYAAAKRAATTGRCGG RRRSSC-3') and U1R (5'CGGGCGGTGTGTRCAARR SSC-3') at a final concentration of $0.2 \mu \mathrm{M}$ (Rivas et al., 2004). PCR conditions were as followed: pre-heating at $95{ }^{\circ} \mathrm{C}$ for 9 min; 35 cycles of denaturing at $95^{\circ} \mathrm{C}$ for $1 \mathrm{~min}$; annealing at $55^{\circ} \mathrm{C}$ for $2 \mathrm{~min}$; extension at $72^{\circ} \mathrm{C}$ for $1 \mathrm{~min}$; and a final extension at $72{ }^{\circ} \mathrm{C}$ for 7 min (Rivas et al., 2004). The amplified PCR product was purified and sequenced, after which the sequence was aligned with similar well-known sequences obtained from the National Center for Biotechnology Information (NCBI) database and CBSKNAW Fungal Biodiverisity Centre database.

\section{Experimentation and statistical analysis}

The significance of difference between each test variable was determined using one-way analysis of variance (ANOVA) and least significance test, computed using SPSS version 11.5 software. Tukey honest significant difference (HSD) and Duncan's multiple range test were used for multiple comparisons of means. Significance was considered established at $p<0.05$. All the presented data in graphs and tables were the means of three replicates.

\section{RESULTS AND DISCUSSION}

A total of 95 native fungal isolates were isolated and purified from 12 locations around Penang, Malaysia. From this fungal collection pool, most of the isolates $(80 \%)$ were able to survive on cellulose agar selective medium, utilizing cellulose as the major carbon source during preliminary screening. Out of these potential cellulaseproducing fungal isolates, 79 isolates which showed rapid growth on cellulose agar were selected to carry out submerged fermentation. Twenty three isolates which produced big clear zones $(>2 \mathrm{~cm}$ ) (Figure 1) were selected to serve as the inoculums in solid-state fermentation in order to quantify the cellulase and xylanase production. In order to select the best native isolate more precisely, SSF process was performed using oil palm frond (OPF) as the substrate (Table 1). Fungal isolate DWA8, originated from decayed wood material, was proved to be the best fungus which exhibited the highest FPase activity $(2.57 \mathrm{U} / \mathrm{g})$ and xylanase activity $(4.12 \mathrm{U} / \mathrm{g}$ ) respectively (Table 1$)$. Although it did not secrete the highest amount of CMCase enzyme, DWA8 could still be considered as among the top CMCase producers, with $0.98 \mathrm{U} / \mathrm{g}$ compared to $1.08 \mathrm{U} / \mathrm{g}$ (the highest activities) showed by fungal isolate RB02. Hence, DWA8 was chosen as the most promising strain to be subjected to successive physical mutagenic treatments with microwave and UVC irradiation. At the same time, this wild strain was being identified as Aspergillus niger (GenBank accession no. KP299287) by pairwise sequence alignment from a PCR product of approximately $500 \mathrm{bp}$. This fragment size was in close match with the fragment size (508 for eukaryotes) amplified by a single primer set targeted the Universal Amplified Ribosomal Region (UARR) (Rivas et al., 2004). The UARR sequence allows rapid identification due to its smaller size using only one same primer pairs compared with the 16S rRNA gene and 18S rRNA gene. Moreover, it allows microbial differentiation between phylogenetically closed species from the same genus, in both prokaryotes and eukaryotes (Rivas et al., 2004).

Spore suspension of parental DWA8 was subjected to microwave irradiation at different time intervals for a period of $180 \mathrm{sec}$. To obtain the lethality after the treatment of microwave, both the mutated strains and the un-irradiated isolate (control) were cultured onto $\mathrm{CMC}-\mathrm{Na}$ screening media containing PDA and TritonX-100. Remarkably, lethality rate of DWA8 spores hit $73 \%$ after $30 \mathrm{sec}$ of treatment, the second highest rate compared to the $75 \%$ achieved after 180 -second treatment (Figure 2). Meanwhile, the lethality rate of our fungus did not increase proportionally from 60 -second to 150 -second treatment period. Hence, 5 mutant individuals originated from 30 second and 80-second respectively were selected to be used as inoculums in SSF process to investigate the effect of microwave radiation on cellulase production. MV 305 was the best mutant among the ten isolates tested (Figure 3), by secreting 3.14 U/g FPase compared to 2.57 $\mathrm{U} / \mathrm{g}$ from control (DWA8).

Besides, CMCase production was enhanced by $38.8 \%$. In addition, statistical analysis indicated significant differences $(p<0.05)$ in FPase and CMCase activities exhibited by MV 305 compared with other mutants tested. 

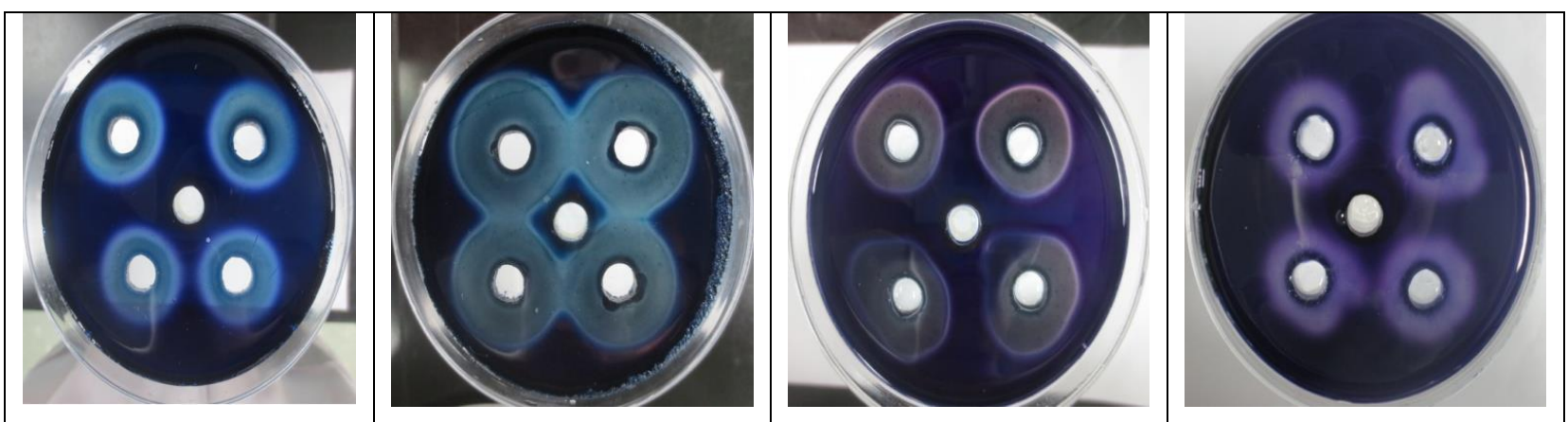

Figure 1: Clearing zone (halo) formations on CMC selective agar with the cross-linking between $\mathrm{HCl}$ and Congo Red. From left: fungal isolate DWA7; SC01; DWA5 and T16II.

However, for Xylanase production, among the mutant population tested only MV 303 showed increased production compared with DWA8 (control). Although there was a slight decrease of Xylanase activity in MV 305, it was the second best secretor after MV 303 and statistical analysis showed the reduction was not significant $(p>0.05)$. Therefore, MV 305 was selected to undergo further mutation treatment.

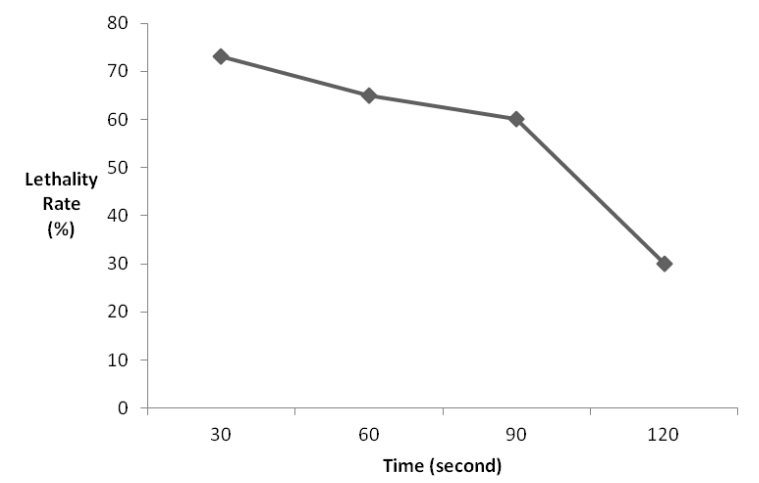

Figure 2: Lethality rate of DWA8 spores exposed to microwave irradiation at different time intervals. Individual treatment time and colony plating was carried out in triplicate.

It is claimed that microwave energy consists of electric and magnetic fields that are able to penetrate deep into biological materials. The ability of microwave irradiation to induce mutational event has been studied, with its bioeffects being reported of causing cell damage due to oxidative stress and DNA damage (Lin et al., 2012). Genetically speaking, it could result in DNA strand breakage and point mutation. By putting Trichoderma and Lactobacillus species within household microwave oven in a period of time, their survival rate was decreased with the increment of treatment period, until the achievement of 100\% lethality rate (Li et al., 2010; Lin et al., 2012). However, this was not the case in our microwave mutational treatment process. Only $75 \%$ of our fungal isolates DWA8 were killed at maximum treatment time of $180 \mathrm{sec}$. The difference in microbial sensitivity towards microwave irradiation might be due to the fungal cell wall and pigmentation of the Aspergillus spores. The spore of
Aspergillus niger possesses a black-pigmented, multilayered and highly ornate spore wall (Anderson et al., 2000). This acted as a good shield, thus may well-explain why our fungal isolate was not sensitive to irradiation. Known as melanin, this pigment increases the survival chances and longevity of fungal spores, protecting the spore before reaching the right time of germination (Begum et al., 2009). Nonetheless, with 30-second microwave treatment, approximately $22 \%$ increment in FPase activity and $38.8 \%$ increment in CMCase activity were shown by MV 305, the best performed mutant survived from $73 \%$ killing rate.

Lethality rate of MV 305 mutant under UVC irradiation increased proportionally with treatment time, and it hit 99\% after 10-minute UVC treatment (Figure 4). Since the treatment time of 6 min already gave $90 \%$ lethality rate, 3 mutant individuals originated from 6,8 and $10 \mathrm{~min}$ treatment time had been picked and purified as single isolates into PDA plates after they showed their abilities to grow on CMC-Na screening plates during colony counting. UVC treatment analysis indicated that mutant UVC 8ii showed the highest increased in both FPase and grow on CMC-Na screening plates during colony counting. UVC treatment analysis indicated that mutant UVC 8ii showed the highest increased in both FPase and CMCase activities among the mutant population (Figure 5). It showed $69 \%$ increase in CMCase activity compared to controlled strain of MV 305

Short wavelength $(254 \mathrm{~nm})$ ultraviolet (UV) light belongs to type $C$ of UV. Falling in the range of 250 $260 \mathrm{~nm}$ which is considered to be lethal to most microorganisms such as fungi, bacteria, yeast, viruses, protozoa and algae (Begum et al., 2009; Menetrez et al., 2010), it is mainly utilized in microbial inactivation on commercial and clinical occasions or research setting for mutant development. The inactivation of fungal isolate MV 305 by UVC irradiation was obviously dose dependent which was in agreement with Menetrezet et al., (2010); Nourmoradi et al., (2012).

Furthermore, an increment of $69 \%$ in CMCase activity was shown in MV 305 . During the sequence analysis of endoglucanase I genes encoding CMCase enzymes, some base mutations that led to amino mutations could be the reason for enhanced cellulase production ( $\mathrm{Li}$ et al., 2010. 


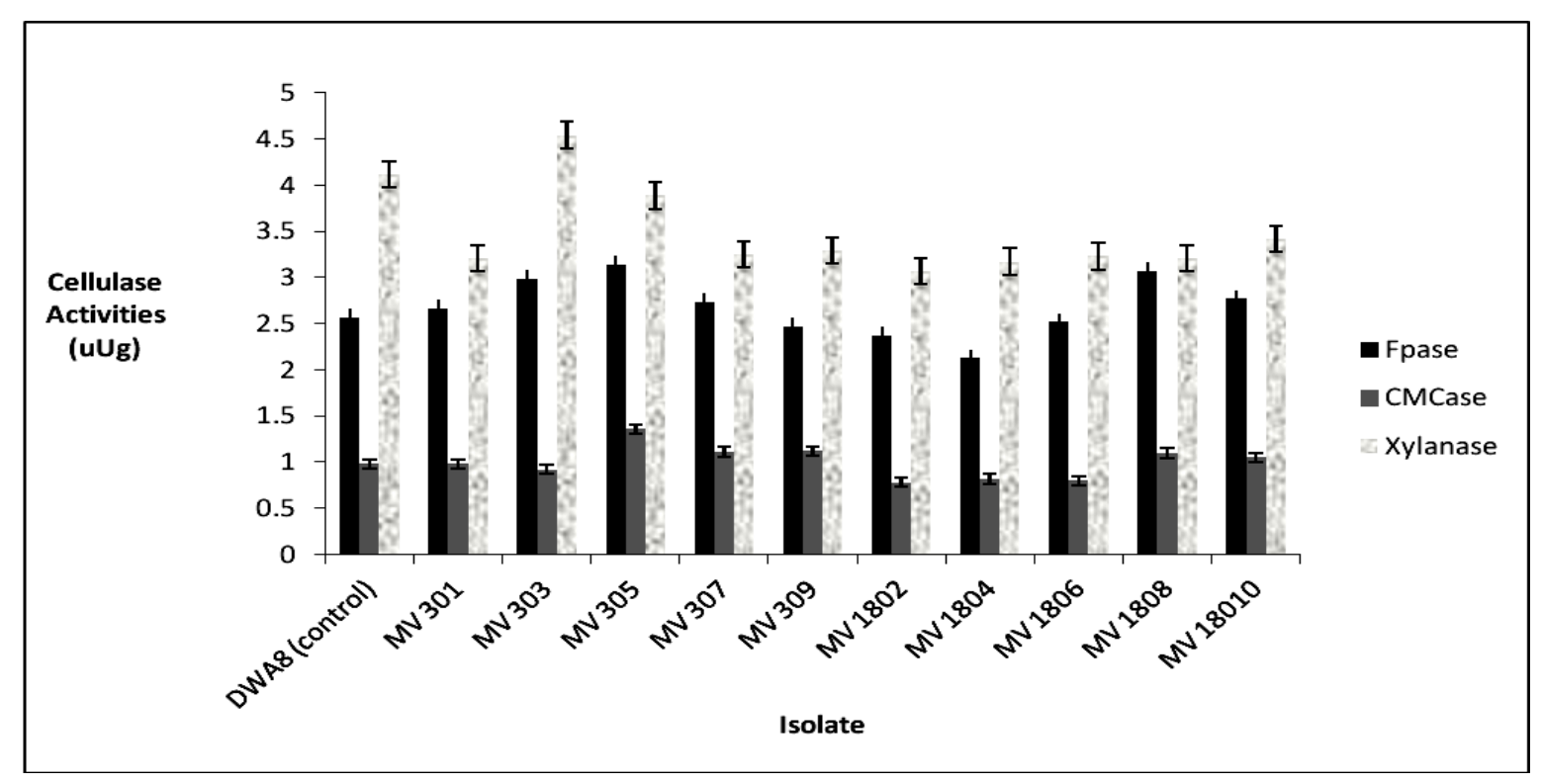

Figure 3: Cellulase activities of microwave-treated DWA8 spores after 7-day cultivation in solid-state fermentation. Experiment was carried out in triplicates during SSF. MV 301, MV303, MV 305 and MV 307 were the individual mutants generated during 30-second of microwave treatment, while MV 1802, MV 1804, MV 1806, MV 1808 and MV 18010 were the individual mutants generated from 180-second microwave treatment.

Table 1: The cellulase activities produced by various native wild-type fungal isolates. The activities for each isolate were the mean values from triplicates during SSF experiment.

\begin{tabular}{lccc}
\hline Isolate & FPase Activity $(\mathrm{U} / \mathrm{g})$ & CMCase Activity $(\mathrm{U} / \mathrm{g})$ & $\begin{array}{c}\text { Xylanase Activity } \\
(\mathrm{U} / \mathrm{g})\end{array}$ \\
\hline T17II & 0.63 & 0.12 & 0.25 \\
DWA1 & 0.86 & 0.23 & 0.42 \\
RP02 $(\mathrm{W})$ & 1.09 & 0.21 & 0.39 \\
DWB03 & 0.85 & 0.24 & 0.25 \\
opT6I & 1.37 & 0.78 & 0.87 \\
DWA8 & 2.57 & 0.98 & 4.12 \\
RP02 (G) & 1.34 & 0.96 & 0.78 \\
DWA5 & 1.33 & 1.00 & 0.57 \\
D12I & 1.13 & 0.76 & 0.84 \\
D18I & 1.81 & 1.00 & 1.11 \\
DWB2II & 1.56 & 1.07 & 1.20 \\
T16II & 1.34 & 0.96 & 1.02 \\
RB02 & 2.24 & 1.08 & 0.34 \\
DWA1II & 0.47 & 0.41 & 0.20 \\
DWA7 & 0.76 & 0.64 & 3.00 \\
DWC & 1.05 & 0.52 & 2.09 \\
RB2 & 0.85 & 0.58 & 2.69
\end{tabular}




\begin{tabular}{llll} 
DWA6 & 0.84 & 0.49 & 0.21 \\
BT01 & 1.51 & 0.22 & 3.53 \\
DWB02 & 1.30 & 0.21 & 0.15 \\
DWB3 & 0.71 & 0.19 & 3.32 \\
SC01 & 0.62 & 0.25 & 0.21 \\
T17I & 0.57 & 0.13 & 0.17 \\
\hline
\end{tabular}

Apart from dosage (the function of time, distance and irradiance), UV penetration and absorption are also the factors that determine the efficacy of UV irradiation (Begum et al., 2009). UVC light needs to be applied directly onto smooth surfaces or transparent materials in order to fully exert its killing ability, and to cater to this purpose, UVC was shone directly onto an open lid petri dish filled with spore suspension during treatment. Furthermore, spore suspension was suspended in Tween80 , the famous surfactant in providing homogenous distribution of spore in water. The volume of spore suspension to be sent for UVC irradiation was maintained as smaller as possible, so that protective effect of the thickness of liquid layer could be reduced.

Alkylating agents such as ethyl methanesulfonate (EMS) induces chemical modification of nucleotides, which results in mispairing and base changes (Kim et al., 2006). It is claimed that EMS proved to be more effective compared to physical mutagens such as UV as it enhanced cellulase activity to the greater extent (Shafique et al., 2011). Under the temperature of $30^{\circ} \mathrm{C}$ (fungal optimal growth temperature) and 8-hour incubation period using EMS concentration in the range of $1.0-3.0 \%(\mathrm{v} / \mathrm{v})$, the lethality rate of UVC8ii increased proportionally with the raise of concentration (Figure 6). Out of the 8 colonies isolated from mutant E2.50 and E3.00 respectively, mutant E3.06 showed 48\% increase in FPase activity and $83 \%$ increase in xylanase activity (Figure 7). However, only $6.5 \%$ increment of CMCase activity was possessed by another mutant, E2.52, as most of the mutants faced decrement in this particular enzyme.

Although there was an enhancement in FPase and Xylanase activities in mutant E3.06, it was considered to be insignificant statistically. Besides, EMS treatment also gave almost no improvement for the case of endoglucanase. In the work of Arun and his co-workers (2014), second round of EMS treatment failed to further increase the activities of the selected mutants, and no obvious improvement was achieved in $A$. niger treated with EMS compared to $77 \%$ CMCase increase in EMS treated Trichodermaviride. Thus, the mutagenic randomness of EMS causing reversions and instability in genomes of fungi (Arun et al., 2014) may be the cause of unpredictability. Since the understanding of EMS mediated mutation upon microbial genomes and upon

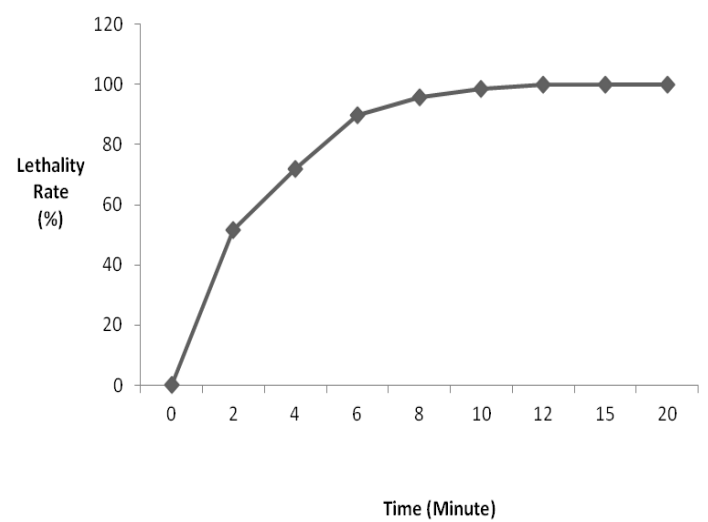

Figure 4: Effect of UV exposure on the percentage kill of MV 305 at different time intervals. Every mutation treatment and plating process was carried out in triplicate.

their cellulase genes is still under establishment, more effort is required to elucidate this relationship on molecular and biochemical basis (Fennington et al., 1984; Kotchoni et al., 2006).

Meanwhile, Pradeep and Narasimha (2011) had successfully created an Aspergillus mutant with 15-fold and 14-fold increment in CMCase and FPase respectively, a However, the substrate being used, the pea seed husk, was different from the current study. Moreover, it was chemically pre-treated with hydrogen peroxide. Multiple exposures to EMS and ethidium bromide had created a Trichoderma mutant with 2.14-fold and 2.10-fold increase in FPase and endoglucanase (Chandra et al., 2009).fter EMS treatment (Pradeep and Narashimha, 2011). EMS mutant originated from Trichoderma conidia treated colchicines also showed approximately 2 -fold increase in cellulase production (Toyama and Toyama, 2000). Since their treatment schemes were different from current study, thus it is possible that the mechanism or type of genetic changes that had taken places before EMS induction may differ from present study too. Besides Aspergillus and Trichoderma species, the Penicillium species is another filamentous fungus which has been shown to produce an enzyme mixture with better ratio of FPase activity and $\beta$ glucosidase, an instrumental property in cellulose hydrolysis (Syed et al., 2013; Schneider et al., 2014). Mutation treatment of EMS followed by UV irradiation had enable Adsul and co-workers (2009) to create a Penicillium mutant with 3-5 fold of FPase, CMCase and xylanase during SSF on wheat bran and pure cellulose 


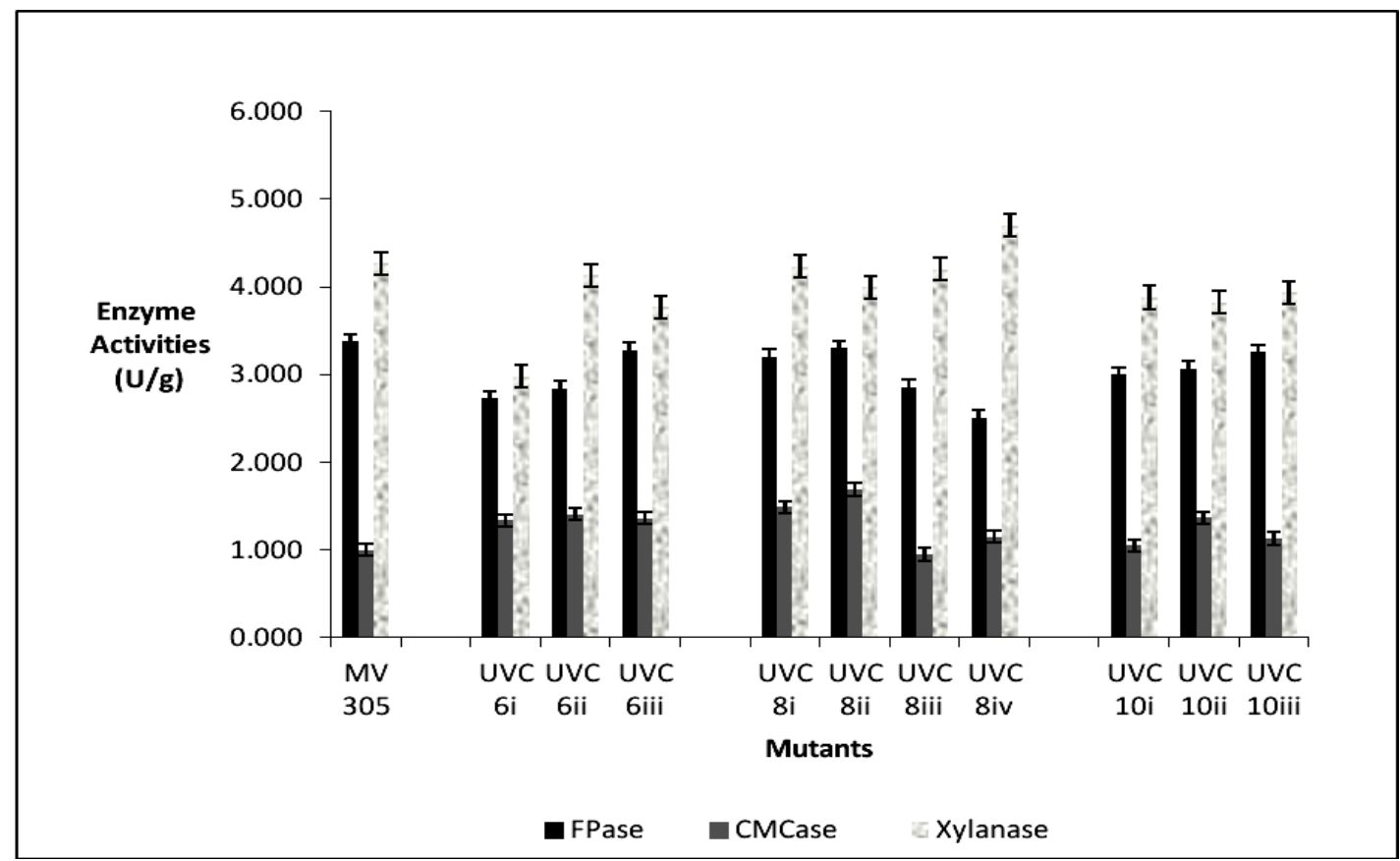

Figure 5: Enzyme production of MV 305 (control) and its derivatives mutated by UVC irradiation. Enzyme activities were obtained from the mean values of triplicate flasks. MV305 was the microwave mutant which secretes the highest cellulase enzymes among the other mutants; UVC 6i, UVC 6ii and UVC 6iii were individual mutants generated after 6 second of UVC radiation treatment; UVC 8i, UVC 8ii, UVC 8iii and UVC 8iv were individual mutants generated under 8second of UVC treatment; UVC 10i, UVC 10ii and UVC 10iii were individual generated from 10-second UVC treatment.

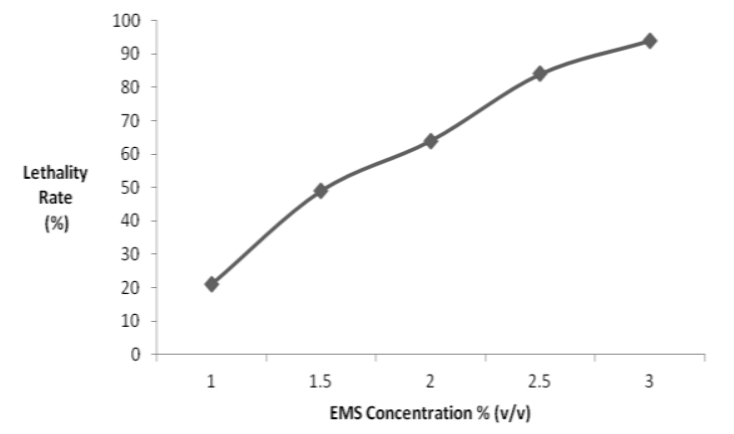

Figure 6: Lethality rate of UVC8ii plotted over the administered dosage of EMS exposure. Experiment was carried out in triplicates.

(Adsul et al., 2009). Similar treatment had been used by Liu and co-workers (2011) in generating Penicillium mutant with higher cellulase activity (larger hydrolysis zone during qualitative plate screening) (Liu et al., 2011). Hence, it is hard to compare their result with current study, due to the differences in substrate and microorganism chosen. In conclusion, it can be said that this paper is the first initiative to examine the combined effect of microwave, UV Irradiation and EMS upon cellulases and xylanase activities in $A$. niger. These mutagens are effective and easily accessible in creating highly productive fungal strain, thus they deserve serious attention to be fully developed as an established mutational mechanism among filamentous fungi. Meanwhile, by providing financial advantages such as reduced energy, space requirement and the simplicity of the equipment used, compared to the submerged fermentation, solid-state fermentation has a higher potential as a platform in providing feedstock for SGB.

\section{CONCLUSION}

From preliminary screening, a fungal strain originated from the decayed wood has been successfully isolated as the best candidates among the native wild species to be further developed by mutagenesis. The compounded effects of microwave, UVC and EMS have produced an $A$. niger MUE3.06 mutant with an overall increase of $114 \%$ in CMCase activity, $72.57 \%$ in FPase activity and $70.65 \%$ in Xylanase activity compared with the parental DWA8 strain.

\section{ACKNOWLEDMENT}

This work was mainly financed by USM short term grant (304/PTEKIND/6311130). The author (Miss Tai Wan Yi) would like to express her greatest appreciation and gratitude to Ministry of Higher Education (MOHE) for giving her Mybrain (My master) scholarship. Special thanks to Professor Kim Keun and Professor Wong Sek Man for their kindness and generosity in providing technical support via personal communication. 


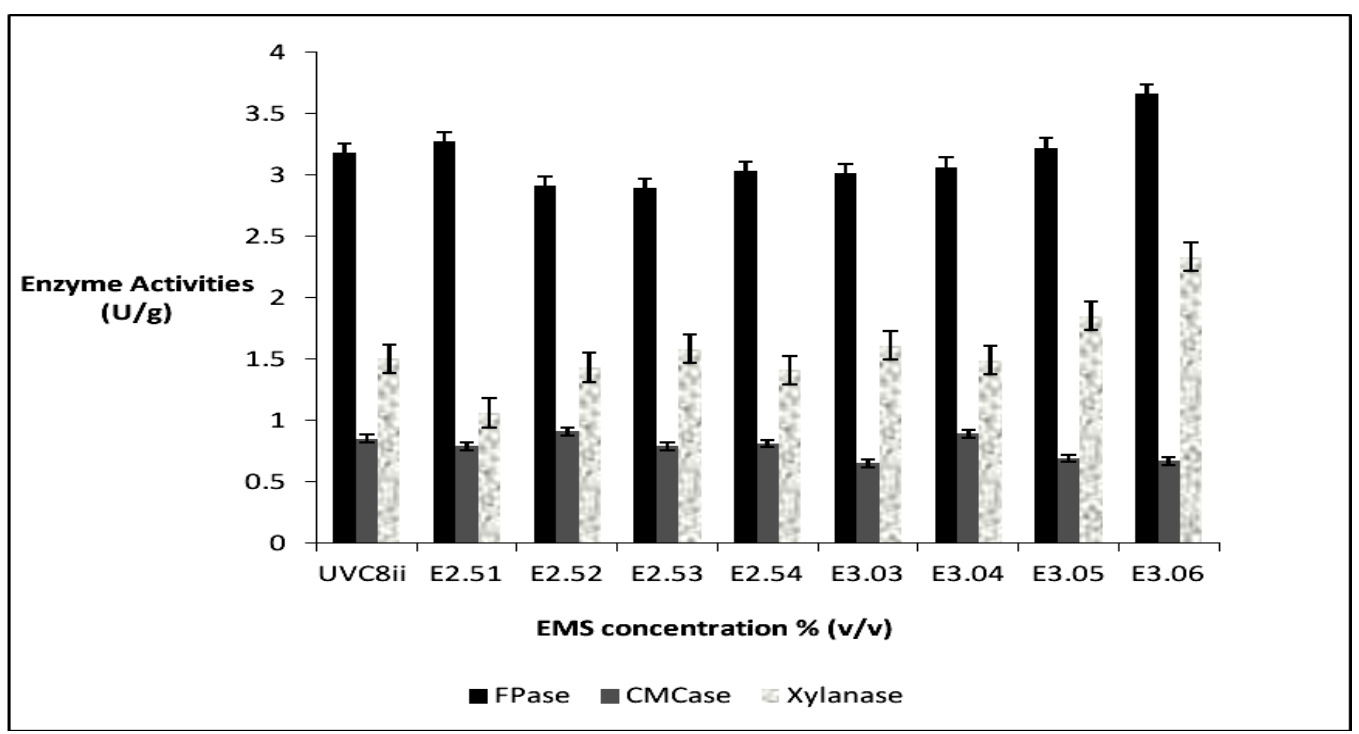

Figure 7: Cellulase activities of EMS treated UVC8ii spores after 7-day cultivation in solid-state fermentation. The enzyme analysis was performed in triplicate for each mutant. UVC 8ii was the highest enzyme secretor among other UVC mutants; E 2.51, E 2.52, E 2.53 and E 2.54 were the individual mutants created under 2.5\% of EMS treatment; E 3.03, E3.04, E 3.05 and E3.06 were mutants originated from 3.0\% of EMS. Each and every of these mutants was treated as a unique entity of themselves.

\section{REFERENCES}

Adsul, M. G., Terwadkar, A. P., Varma, A. J. and Gokhale, D. V. (2009). Cellulases from Penicillium janthinellum mutants: Solid-state production and their stability in ionic liquids. Bioresources 4(4), 1670-1681.

Anderson, J. G., Rowan, N. J., MacGregor, S. J., Fouracre, R. A. and Farish, O. (2000). Inactivation of food-borne enteropathogenic bacteria and spoilage fungi using pulsed-light. IEEE Transactions of Plasma Science 28(1), 83-88.

Arun, P., Suhas, V. B., Naveen, S. and Ravishanka, H. N. (2014). Study on the synergistic action of cellulase systems from Trichoderma and Aspergillus mutants on carboxy methyl cellulose. The Scitech Journal 1(1), 25-28.

Balat, M. (2011). Production of bioethanol from lignocellulosic materials via the biochemical pathway: A review. Energy Conversion and Management 52(2), 858-875.

Barbour, L., Hann, A. M. and Xiao, W. (2006). Mutagenesis. Methods in Molecular Biology 313, 121 127.

Begum, M., Hocking, A. D. and Miskelly, D. (2009). Inactivation of food spoilage fungi by ultraviolate (UVC) irradiation. International Journal of Food Microbiology 129, 74-77.

Chand, P., Aruna, A., Maqsood, A. M. and Rao, L. V. (2005). Novel mutation method for increase cellulase production. Journal of Applied Microbiology 98, 318323.

Chandra, M., Kalra, A., Sangwan, N. S., Gaurav, S. S., Darokar, M. P. and Sangwan, R. S. (2009).
Development of a mutant of Trichoderma citrinoviride for enhanced production of cellulases. Bioresource Technology 100, 1659-1662.

Derkx, P. M. F., Janzen, T., Sorensen, K. I., Christensen, J. E., Stuer-Lauridsen, B. and Johansen, E. (2014). The art of strain improvement of industrial lactic acid bacteria without the use of recombinant DNA technology. Microbial Cell Factories 13, 1-13.

Dose, K., Bieger-Dose, A., Dillmann, R., Gill, M., Kerz, O., Klein, A. and Stridde, C. (1996). UV photobiochemistry under space conditions. Advanced Space Research 18(12), 1251-1260.

Ennis, D. G. (2001). Mutagenesis. Encyclopedia of Life Sciences 1-8.

Fennington, G., Neubauer, D. and Stutzenberger, F. (1984). Cellulase biosynthesis in a catabolite repression resistant mutant of Thermomonospora curvata. Applied and Environmental Microbiology 47(1), 201-204.

Gessesse, A. and Gashaw, M. (1999). High-level xylanases production by an alkaliphilic Bacillus $\mathrm{sp}$. by using solid-state fermentation. Enzymes and Microbial Technology 25, 68-72.

Gessesse, A. and Gashe, B. A. (1997). Production of alkaline xylanase by an alkaliphilic Bacillus $\mathrm{sp}$. isolated from an alkaline soda lake. Journal of Applied Microbiology 83, 402-406.

Ghose, T. K. (1987). Measurement of cellulase activities. Pure and Applied Chemistry 59(2), 257-268.

Goh, C. S., Tan, K. T., Lee, K. T. and Bhatia, S. (2010). Bio-ethanaol from lignocelluloses: Status, perspectives 
and challenges in Malaysia. Bioresource Technology 101(13), 4838-4841.

He, J., Yu, B., Zhang, K. Y., Ding, X. M. and Chen, D. W. (2009). Strain improvement of Trichoderma reesei Rut C-30 for increased cellulase production. Indian Journal of Microbiology 49, 188-195.

Kim, Y. S., Schumaker, K. S. and Zhu, J. K. (2006). EMS mutagenesis of Arabidopsis. Methods in Molecular Biology 323, 101-103.

Kodym, A. and Afza, R. (2003). Physical and Chemical Mutagenesis. Methods in Molecular Biology: Plant Fuctional Genomics: Methods and Protocols. Humana Press, Inc., Totowa, NJ. 236, 189-204.

Kotchoni, S. O., Gachomo, E. W., Omafuvbe, B. O. and Shonukan, O. O. (2006). Purification and biochemical characterization of carboxymethyl cellulase (CMCase) from a catabolite repression insensitive mutant of Bacillus pumilus. International Journal of Agricultural and Biology 8(2), 286-292.

Kovacs, K., Megyeri, L., Szakacs, G., Kubicek, C. P., Galbe, M. and Zacchi, G. (2008). Trichoderma atroviride mutants with enhanced production of cellulase and $\beta$-glucosidase on pretreated willow. Enzyme and Microbial Technology 43(1), 48-55.

Li, X. H., Yang, H. J., Roy, B., Park, E. Y., Jiang, L. J., Wang, D. and Miao, Y. G. (2010). Enhanced cellulase production of the Trichoderma viride mutated by microwave and ultraviolet. Microbiological Research 165(3), 190-198.

Lin, H. L., Chen, X. M., Yu, L. J., Xu, W., Wang, P., Zhang, X., Li, W. G., Li, C. H. and Ren, N. Q. (2012). Screening of Lactobacillus rhamnosus strains mutated by microwave irradiation for increased lactic acid production. African Journal of Microbiology Research 6(31), 6055-6065.

Liu, Y. T., Luo, Z. Y., Long, C. N., Wang, H. D., Long, M. N. and Hu, Z. (2011). Cellulase production in a new mutant strain of Penicillium decumbens ML-017 by solid state fermentation with rice bran. New Biotechnology 28(6), 733-737.

Menetrez, M. Y., Foarde, K. K., Dean, T. R. and Betancourt, D. A. (2010). The effectiveness of UV irradiation on vegetative bacteria and fungi surface contamination. Chemical Engineering Journal 157, 443-450.

Nagel, F. J. J., Tramper, J., Bakker, M. S. N. and Rinzema, A. (2001). Model for online moisture content control during solid state fermentation. Biotechnology and Bioengineering 72(2), 231-243.

Nourmoradi, H., Nikaeen, M., Stensvold, C. R., Mirhendi, H. (2012). Ultraviolet irradiation: An effective inactivation method of Asperigillus spp. in water for the control of waterborne nosocomial aspergillosis. Water Research 46, 5935-5940.

Pang, P. K., Ibrahim, D., Pappe, H., Szackacs, G. and Omar, I. C. (2006). Production of cellulolytic enzymes by a newly isolated, Trichoderma sp. FERL C3-2 via solid-state fermentation grown on sugarcane baggase: Palm kernel cake as substrates. Pakistan Journal of Biological Sciences 9(8), 1430-1437.
Polizeli, M. L. T. M., Rizzatti, A. C. S., Monti, R., Terenzi, H. F., Jorge, J. A. and Amorim, D. S. (2005). Xylanases from fungi: Properties and industrial applications. Applied Microbiology and Biotechnology 67, 577-591.

Pradeep, M. R. and Narasimha, G. (2011). Utilization of pea seed husk as a substrate for cellulase production by mutant Aspergillus niger. Insight Biotechnology 1(2), 17-22.

Raimbault, M. and Alazard, D. (1980). Culture method to study fungal growth in solid fermentation. European Journal of Applied Microbiology and Biotechnology 9, 199-209.

Rivas, R., Velazquez, E., Zurdo-Pineiro, J. L., Mateos, P. F. and Molina, E. M. (2004). Identification of microorganisms by PCR amplification and sequencing of a universal amplified ribosomal region present in both prokaryotes and eukaryotes. Journal of Microbiological Methods 56, 413-426.

Schneider, W. D. H., Reis, L. R., Camassola, M. and Dillon, A. J. P. (2014). Morphogenesis and production of enzymes by Penicillium echinulatum in response to different carbon sources. BioMed Research International 2014, 1-10.

Shafique, S., Bajwa, R. and Shafique, S. (2011). Strain improvement in Trichoderma viride through mutation for overexpression of cellulase and characterization of mutants using random amplified polymorphic DNA (RAPD). African Journal of Biotechnology 10(84), 19590-19597.

Smits, J. P., Rinzema, A., Tramper, J., Van Sonsbeek, H. M. and Knol, W. (1996). Solid-state fermentation of wheat bran by Trichoderma reesei QM9414: Substrate composition changes, c balance, enzyme production, growth and kinetics. Applied Microbiology and Biotechnology 46, 489-496.

Steensels, J., Snoek, T., Meersman, E., Nicolino, M. P., Voordeckers, K. and Verstrepen, K. J. (2014). Improving industrial yeast strains: Exploiting natural and artificial diversity. FEMS Microbiology Reviews 38, 947-995.

Swift, J. (1972). The estimation of mycelial biomass by determination of the hexosamine content of wood tissues decayed by fungi. Soil Biological and Biochemistry 5, 321-322.

Syed, S., Hassan, S. R. U. and Johri, S. (2013). A novel cellulase from an endophyte, Penicillium sp. NFCCI 2862. American Journal of Microbiological Research 1(4), 84-91.

Taneja, K., Gupta, S. and Kuhad, R. C. (2002). Properties and application of a partially purified alkaline xylanase from an alkalophilic fungus Aspergillus nidulans KK-99. Bioresource Technology 85(1), 39-42.

Theather, R. M. and Wood, P. J. (1982). Use of congo red polysaccharide interactions in enumeration and characterization of cellulolytic bacteria from the bovine rumen. Applied and Environmental Microbiology 43(4), 777-780. 
Mal. J. Microbiol. Vol 12(1) 2016, pp. 91-101

Toyama, H. and Toyama, N. (2000). Successive constraction of cellulase hyperproducers of trichoderma using hyperpolyploids. Applied Biochemistry and Biotechnology 84-86, 419-430. 